\title{
Two Linguistic Case Studies of the Craft of Songwriting 'Imagine' and 'Like a Rolling Stone'
}

by Matthew Hewett

On the surface, a medley of notes, chords, sounds, and words may strike the naïve listener as commonplace and natural. Songwriting might superficially appear to conceal simple combinations of constitutive elements and motifs in other words, setting 'natural language' to a tune. But this assessment would be deeply flawed. Every note, every chord, and every word is purposeful and powerful, particularly when the pen is wielded by an expert songwriter. While numerous linguistic devices are available to any speaker of the language in question, a master songwriter is capable of exploiting these devices for subtle effects. Furthermore, the effective implementation of these devices consciously and subconsciously affects the listenership. The two songs "Imagine" and "Like a Rolling Stone", written by John Lennon and Bob Dylan respectively, demonstrate an acute awareness of the expressive force communicated via particular grammatical constructions, lexemes, tense/aspect combinations, and other linguistic phenomena. Lennon and Dylan brandish their linguistic savvy by connecting with their audiences, albeit in fundamentally different ways. This paper seeks to compare how two of the most famous singer/songwriters of the late $60 \mathrm{~s}$ and early $70 \mathrm{~s}$ variably connected with and manipulated their listenership. Furthermore, it seeks to demonstrate how a close linguistic analysis contributes to the general understanding of the momentous socio-cultural responses these songs elicited in popular culture. The methodology involves a close investigation of linguistic forms, including line-by-line analyses and comparisons between the two writers (see the Appendix for the author's transcriptions of the lyrical content of both songs).

"Imagine" was written, recorded, and released by John Lennon in 1971 (Jeffrey). It provided a voice for a generation opposed to the political corruption and militaristic climate of the United States in the late 1960s. The content is, in Lennon's own words, "anti-religious, anti-nationalistic, anticonventional, anti-capitalistic, but because it is sugar-coated, it is accepted" (Henke 49). Clearly, the song's controversial content had the potential to initiate societal rifts; and so it did, especially among some religious groups with the opening lyric, "Imagine there's no heaven". However, as the above quote demonstrates, Lennon was attuned to the meaningful relationship between a song's lyrical content, its message, and its audience. Lennon understood that that by recasting potential heresies and alienating statements as short and sweet depictions of a rose-tinted utopia, he could disseminate his truly powerful message among listeners who might not otherwise have taken notice. This is what made the song so successful.

The linguistic themes of the song are essentially established in the first line: "Imagine there's no heaven." The second person singular imperative 
'Imagine' - a dynamic verb, corresponding to a direct speech act (or command) - demands the listeners' attention and engagement. Note that there is no context for this imperative. Instead, Lennon addresses his listenership suddenly, out of time. It is highly appropriate, then, that the verbal complement of 'imagine' in the following finite, subordinate clause is the existential construction 'there's', grammatically marked as a simple present verb, while it likely connotes a timeless present sense. Furthermore, the existential construction shifts the semantic end-weight of the subordinate clause to 'heaven', the word occupying rhematic position - the locus for new or focused information in the theme rheme analysis of the flow of texts and information. The semantic shift captures and maintains the listener's attention as she awaits the semantic nucleus of the subordinate clause, as if teetering on a fulcrum before the weight drops on the other side. Together, the imperative and the 'timeless present' existential predication stimulate an activist sentimentality and demand that the listener imagine a better world. The content of the message is imminently present in the moment of playback since Lennon's voice speaks without temporal constraints - a personal and direct message to every audience. Lennon employs this device consistently throughout the piece.

Furthermore, Lennon manipulates English negation, which might otherwise be overlooked, to alter his audience's perception of his proposed better world. Frequently after 'imagine', Lennon uses an affirmative existential predication followed by a noun phrase (NP) with local negation in the determiner (e.g. "Imagine there's no countries"; "Imagine there's... nothing to kill or die for, and no religion too."). It is notable that the contraction 'there's' is not conjugated according to the grammatical features of the subject and resists Standard Written English number agreement rules; this may create a sense of lyrical rhythm and stability. The affirmative existential predication implies that the absence of these unwanted things is both imaginable and tangible in some sense. This construction differs from "Imagine there aren't/isn't any countries," as the statehood of 'a world without countries' is in itself a preferable state. In other words, 'a world without countries' is just as much of a tenable, positivistic idea as is 'a world with countries'. This subtlety augments the positive imagery that Lennon paints with each artistic stroke. He does not bluntly call for a world without, e.g., religion, but encourages his audience to dare to imagine a place whose identity consists of semantic components such as NO RELIGION and NO COUNTRIES.

In service of his message, Lennon cunningly employs different personal pronouns to engender a sense of communal solidarity and brotherhood which soften and support the 'call-to-action' imperatives. In the third line of the song, Lennon sings, "No hell below us, above us only sky." Before continuing, it is worth noting that Lennon has masterfully used parataxis ("The placing of propositions or clauses one after another, without indicating by connecting words the relation between them" OED) to create a beautifully iconic image of the juxtaposition of heaven and hell - that is, the parallel opposition of what is 'above' and what is 'below'. Yet, it is Lennon's use of 'us' which is even more fascinating. Lennon switches the song's perceptual focus from the addressee to a community of people 
(including Lennon himself), all of whom will exist in harmony in Lennon's proposed world (cf. also "Imagine all the people living for today" [emphasis added]). Lennon softens the commanding force of 'imagine' by coopting the addressee into a community - the 'us' in the lyrics.

This message comes to a head in the chorus, where Lennon exploits the ingroup versus out-group sensibility to subtly suggest that anyone who opposes Lennon's message (i.e. the subject referent in "You may say I'm a dreamer") opposes a coalition of like-minded thinkers: "... but I'm not the only one. I hope someday you'll join us, and the world will be as one." The collective 'us' reassures interested listeners that Lennon's stance offers support. Furthermore, the alteration from imperatives to a first-person perspective in the chorus encourages listeners to take agency and actively participate. The copular constructions in "I'm a dreamer" and "I'm not the only one" extend the 'timeless' sensibility explored above. Nevertheless, Lennon extends the temporal framework of the song at the end of the chorus with the modal 'will' and the adverb 'someday' in the subordinated complement of the verb 'hope' to anticipate future change: "I hope someday you'll join us, and the world will be as one". Interestingly, the coordinating conjunction which begins the final clause of the chorus conceivably implies a sequence of events, wherein global peace and harmony are the logical conclusions of critics submitting to this ideological framework. In this analysis, 'and' should mean 'whereupon', suggesting a type of hypothetical, if-then relationship between the clauses.

In sum, Lennon's lyrics require an active listener and draw particular attention to his subtle manipulation of standard English phrase structure, hefting significant semantic weight onto sparsely introduced novel words. Consider, for example, the lexical and structural repetition which create a sense of continuity and magnify novel lexemes and slight alterations to the text's predictable format. Dylan's lyrics in "Like a Rolling Stone", on the other hand, demand close attention to the near stream-of-consciousness waterfall of words. Dylan utilizes this cascade to engender particular (negative) attitudes towards characters in the narrative and more generally toward contemporaneous political situations.

"Like a Rolling Stone" was written, recorded, and released by Bob Dylan in 1965 (Greene). It was the biggest hit of Dylan's career and challenged radio DJs' notions of what constituted 'radio songs' - this being six minutes and ten seconds long (ibid). While it did not have the same association with political turmoil that Lennon's "Imagine" did, it profoundly shaped the way that Dylan associated with the 1960's Folk Revival given the song's electric instrumentation - heresy to fans of folk music at the time (ibid). This song marks a significant shift in Dylan's career, and exhibits his penchant for textheavy songs - a quality that is ideal for linguistic analysis.

Before engaging these lyrics, a few pertinent differences between Lennon's and Dylan's styles ought to be presented, as they will be repeatedly highlighted throughout this analysis. The principal difference between the two is their use of text: Dylan is text-heavy (arguably text-centered), while Lennon's lyrics are meaning-centered and relatively bare; note the elliptical character of the text in "Imagine" which abandons the overt repetition of verbs and predicates (e.g. line 15: "[imagine there's] no need for greed or 
hunger"), subordinators (e.g. line 1: "Imagine [that] there's no heaven"), and coordinating conjunctions (e.g. line 3: "No hell below us, [and] above us only sky") in favor of brevity. What's more, the elliptical character of Lennon's lyrics favors an open and engaging cognitive state that listeners apply to 'fill in the gaps' - exactly the sort of mental posture which is conducive for imagination. Conversely, "Like a Rolling Stone" is filled, almost to capacity, with Dylan's lyrics. The song is less participatory and lacks the second person pronominal engagement that benefits Lennon's progressive social message. Instead, Dylan connects with his audience by embodying an authentic, 'working-class' aesthetic and by criticizing the rich and the superficial and relishing in the social plummeting of the derided addressee. This aesthetic establishes common ground between Dylan and his listenership. Dylan organizes the song as a storyteller who narrates, comments, and personally addresses the subject of the story.

The grammatical relationship between the singer and the addressee is fundamentally different in these two songs. While Lennon challenges and supports his listeners, and even provides a platform for them to participate (i.e. a chorus with first person pronouns), Dylan critiques an ambiguous 'you' - conceivably any listener, but arguably some particular referent known by Dylan alone (the latter assessment will be maintained throughout the paper). For example, "Like a Rolling Stone" begins with the following two lines: "Once upon a time you dressed so fine. Threw the bums a dime in your prime, didn't you?" The frozen narrative phrase 'once upon a time' establishes Dylan's role as the narrator and, in conjunction with the simple past verbs 'dressed', 'threw', and 'didn't', dissociates the story from the listener - two typical features of narrative. The tag question 'didn't you', which demonstrates features of Standard English question formation (e.g. do-support with no overt auxiliary, a pronominal copy of the subject 'you', and negative polarity), is normally highly conducive towards responses in conversation. However, since the addressee is unable to respond to Dylan, this tag question emphasizes the accusatory nature of the narrative - that is, Dylan employs the narrative in order to condemn the past actions of the accused individual. Dylan's polemic comes to a crescendo in the chorus with a flurry of derisory, unanswerable questions: "How does it feel - how does it feel - to be on your own, with no direction home, a complete unknown, like a rolling stone?"

Furthermore, the definite article in the noun phrase 'the bums' belies both specific reference to some defined group and also hearer knowledge (that of the addressee) of that group. Dylan presumes that the addressee (though clearly not the listener) knows which 'bums' he references. In doing so, Dylan construes this as a specific event in the past and transforms his critique from general and indifferent to poignant and particular. This narrative appears considerably more 'real' than Lennon's unspecific appeal for peace (cf. Lennon's use of mass and generic nouns: 'heaven', 'hell', 'sky', 'people', 'countries', 'religion', 'peace', 'possessions', 'greed', 'hunger', 'man', etc.).

Authenticity plays an important role in listeners' perception of Dylan and his lyrics, and Dylan exploits the connotations associated with nonstandard English grammar and Germanic-derived words to connect to a working- 
class, American audience. Some general examples of Dylan's nonstandard English include: neutralization of adjective and adverb forms (e.g. 'fine', line 1; 'loud', line 6), use of 'ain't' (e.g. in place of 'isn't', lines 29 and 33; in place of 'haven't', line 48), negative concord (lines 29,48 ), and possibly a third person plural pronoun 'they all', analogous with the nonstandard second person plural pronoun 'you all' (lines 4, 28, and 41; cf. also line 43: "Exchanging all precious gifts."). With these linguistic devices, Dylan aligns himself with a particular social, political, and economic strata and, consequently, differentiates himself from the 'Miss Lonely' type of person that he is reproaching. Dylan also cleverly uses Franco-Latinate (or otherwise inherited) words to deride the addressee's previous lifestyle in lines 31-32, such as 'chrome', 'diplomat', and 'Siamese', while preserving a working-class lexical framework by describing a car as a 'chrome horse'. Unlike Lennon, Dylan clearly differentiates the two socio-economic groups, and apparently opposes them. Dylan's position is readily clear from the lyrical content. Still, he satiates his audience's desire for 'authentic' lyricism and marshals a sense of communal solidarity in the tough street life he portrays for the addressee.

A final salient feature of Dylan's songwriting is that his nuanced and variegated utilization of verbal tense and aspect. The early portion of the text, as previously mentioned, employs simple past verbs (cf. lines 1-2). In line 3, Dylan uses the historical present (formally, simple present) verbs 'call' and 'say' which agree in sense with the preceding simple past verbs, but which add dimensionality to the text. Dylan depicts intermittent portions of his story as imminently present to the listener via simple present verbs. These sections differ markedly from the simple narrative passages and generate temporal ebb and flow. Furthermore, aspectual variation between past habitual (cf. lines 5, 14, 31, and 45), present perfect (cf. lines 13, 15, and 42), present progressive (cf. lines 8,19 , and 41-43), past progressive (cf. lines 4 and 5) and simple present (passim) delicately frames the relationship of events to one another, and suggests their relative importance to both the listener and the addressee. To continue the example given above, the song's lyrical content between lines 1 and 4 takes place entirely in the past and utilizes primarily simple past and present verbs (though Dylan employs other verbs in quoted speech in line 3, and a past progressive in line 4). Beginning in line 5, Dylan creates an aspectual contrast between the past and present with the past habitual construction 'used to laugh'. While this may not entail that the present differs from the past, it strongly implies it, and without a statement to the contrary, the listener understands that something drastic has changed in the addressee's lifestyle. Furthermore, the adverb 'now' in lines 5 and 6 differentiates the following clauses from the previous ones, acting as a functional equivalent to 'but' while simultaneously shifting the narrative lens to the present. By manipulating speakers' expectations and implicational frameworks, Dylan communicates information without even stating it and adds a nuanced dimension of meaning to his lyrics.

The wordplay and subtleties evident in Lennon's and Dylan's lyrics demonstrate their masterful control over the English language and their acute awareness of the nuanced shades of meaning which they evoke 
through a variety of grammatical devices. While each presses different components of the language into service, some similarities may be drawn. Both artists employ verbal aspect to connote a relationship between the speaker, the action, and the listener; Dylan uses numerous aspects to create a moving narrative, similar to the 'rolling stone' metaphor in the song's hook, while Lennon uses the lack of aspectual marking on imperatives to impress a timeless sentimentality in his message. Both artists exhibit an awareness of the semantic minutiae that the determiners contribute to a noun phrase; Dylan uses the definite article to imply prior hearer knowledge of the noun phrase, while Lennon uses mass and generic nouns without definite articles to distance the noun phrases and situate them within a hypothetical space. These features, among others, typify a profound facility which all users of English should strive for - a deep and intimate familiarity with and control over the tools at a speaker's disposal. While average listeners can easily understand these dense and complicated texts, linguistic analysis offers a means with which to peer behind the façade and understand the inner workings of language. As this analysis has demonstrated, linguistics may even offer insight into the minds and writing techniques of two of the greatest singer/songwriters in history.

Imagine

\section{Appendix}

1. Imagine there's no heaven

2. It's easy if you try

3. No hell below us, above us only sky

4. Imagine all the people living for today

5. Imagine there's no countries

6. It isn't hard to do

7. Nothing to kill or die for and no religion too

8. Imagine all the people living life in peace

9. You may say I'm a dreamer

10. But I'm not the only one

11. I hope someday you'll join us

12. And the world will be as one.

13. Imagine no possessions

14. I wonder if you can

15. No need for greed or hunger, a brotherhood of man

16. Imagine all the people sharing all the world

17. You may say I'm a dreamer

18. But I'm not the only one

19. I hope someday you'll join us

20. And the world will live as one.

Like a Rolling Stone 
1. Once upon a time you dressed so fine

2. Threw the bums a dime in your prime, didn't you?

3. People call, say, "Beware doll. You're bound to fall."

4. You thought they were all a'kiddin' you.

5. You used to laugh about everybody that was hanging out.

6. Now you don't talk so loud.

7. Now you don't seem so proud.

8. About having to be scrounging your next meal.

9. How does it feel- How does it feel-

10. To be without a home,

11. Like a complete unknown,

12. Like a rolling stone?

13. Aw, you've gone to the finest schools, alright Miss Lonely,

14. But you know you only used to get juiced in it

15. Nobody's ever taught you how to live out on the street

16. And now you're gonna have to get used to it

17. You say you never compromise

18. With the mystery tramp, but now you realize,

19. He's not selling any alibis,

20. As you stare into the vacuum of his eyes

21. And say, "Do you want to make a deal?"

22. How does it feel- How does it feel-

23. To be on your own,

24. With no direction home,

25. A complete unknown,

26. Like a rolling stone?

27. Aw, you never turned around to see the frowns

28. On the jugglers and the clowns when they all did tricks for you

29. Never understood that it ain't no good

30. You shouldn't let other people get your kicks for you.

31. You used to ride on a chrome horse with your diplomat

32. Who carried on his shoulder a Siamese cat.

33. Ain't it hard when you discover that

34. He really wasn't where it's at

35. After he took from you everything he could steal.

36. How does it feel- How does it feel-

37. (Yell) To be on your own,

38. No direction home,

39. Like a complete unknown,

40. Like a rolling stone? 
41. Aw, princess on the steeple and all the pretty people, they're all drinking,

42. Thinking that they've got it made.

43. Exchanging all precious gifts, but you'd better take your diamond ring

44. You better pawn it, babe.

45. You used to be so amused

46. At Napoleon in rags and the language that he used.

47. Go to him now. He calls you. You can't refuse.

48. When you ain't got nothing, you got nothing to lose.

49. You're invisible now, you got no secrets to conceal.

50. How does it feel- Aw, how does it feel-

51. To be on your own,

52. With no direction home,

53. Like a complete unknown,

54. Like a rolling stone?

\section{Works Cited}

Dylan, B. (1965). Like a rolling stone. On Highway 61 Revisited [Vinyl]. New York: Columbia Records.

Greene, A. (2015). Bob Dylan recorded 'Like a Rolling Stone' 50 years ago today. Rolling Stone Magazine. Retrieved from

http://www.rollingstone.com/music/news/bob-dylan-recorded-like-arolling-stone-50-years-ago-today-20150616?page $=3$

Henke, J. (2003). Lennon legend: An illustrated life of John Lennon. Retrieved from

https://books.google.com/books?id=0mqPf0hnePsC\&pg=PA53\&lpg= PA53\&dq=Anti-religious, + anti-nationalistic, + anti-conventional, +anticapitalistic,+ but + because + it + is + sugarcoated $+i t+i s+$ accepted $\&$ source $=$ bl\&ots=PNUOLVU63m\&sig=7eEqtaZ-

UGUt7I7WL1x0m7u1dew\&hl=en\&sa=X\&ved=0ahUKEwij5tDM1Kj MAhUGNz4KHfZvCm4Q6AEIPzAF\#v=onepage\&q=Antireligious $\% 2 \mathrm{C} \% 20$ anti-nationalistic $\% 2 \mathrm{C} \% 20$ anticonventional $\% 2 \mathrm{C} \% 20$ anticapitalistic $\% 2 \mathrm{C} \% 20$ but $\% 20$ because $\% 20$ it $\% 20$ is $\% 20$ sugarcoated $\% 20$ it $\% 2$ 0is\%20accepted \&f $=$ false

Jeffrey, T. (n.d.). John Lennon music. Universal Music. Retrieved from http://johnlennonmusic.com/ 
Lennon, J. (1971). Imagine. On Imagine [Vinyl]. London: Abbey Road Studios.

Parataxis. (n.d.). In Oxford English Dictionary online. Retrieved from http://www.oed.com.proxy.bc.edu/view/Entry/137669? redirectedFro $\mathrm{m}=$ parataxis\#eid 